\title{
TWO CONGENERIC HEART URCHINS HAVING DIFFERENT ARCHITECTURE AND TROPHIC BEHAVIOR: PALEONTOLOGIC AND ICHNOLOGIC IMPLICATIONS
}

\author{
ASGAARD, Ulla, Geologisk Institut, Øster Voldgade 10, 1350 Copenhagen K, \\ Denmark; JENSEN, Margit, Zoologisk Museum, Universitetsparken 15, 2400 \\ Copenhagen Ø, Denmark; BROMLEY, Richard, G., Geologisk Institut, Øster \\ Voldgade 10, 1350 Copenhagen K, Denmark.
}

The living spatangoid echinoids Echinocardium cordatum and E. mediterraneum were studied in the field (in Greece) and in aquaria (in Denmark) with the aim of elucidating the structure and mode of production of Scolicia-group trace fossils. Using a novel preparation technique, SEM images were produced of the spines in life position.

Animals were kept in aquaria for 18 months and their mode and rate of movement, depth of burrowing and their way of feeding were studied. The function and specializations of the several types of spines were examined.

In the field, narrow aquaria were placed in the sea floor at a site occupied by a lively population of heart urchins. The aquaria were filled with an artificially laminated sediment, from which larger benthic species were excluded. A heart urchin was placed in each narrow aquarium and allowed five days of bioturbation. The animals were then immobilized by rapidly draining the aquaria and the sediment was dried. The narrow aquaria were then $\mathrm{X}$-rayed.

Finally, the sediment was impregnated with epoxy (laterally, by removing a side of the aquarium). The resin penetrated to different depths into the sediment. For this reason, when the remaining loose sediment was removed, this produced, at the epoxy penetration front, detailed "fossil" serial sections of the biogenic structures and revealed the tracemakers in the act of sediment manipulation.

Echinocardium cordatum was confirmed to eat at two distinct levels. Small quantities of surface detritus are consumed at the sea floor, and large quantities of sulfide-rich sediment are swallowed at burrowing level, as much as $20 \mathrm{~cm}$ below sea floor. The latter behavior corresponds with their possession of an intestinal caecum containing sulfide-oxidizing bacterial symbionts.

The trophic style of $E$. mediterraneum was not previously unknown. This species was found to feed exclusively on oxic sediment at burrowing level, a mere 4 $\mathrm{cm}$ below sea floor. The animal proceeds through the sediment in an oblique position, manipulating grains in a "sedimentary laboratory" located in the burrow immediately beneath the mouth.

Although closely related, these two species occupy significantly different trophic positions within their communities. In fossil occurrences of equivalent echinoids, it is unlikely that these trophic styles will be elucidated by anatomical studies; probably only the depth of burrowing (tier depth) may provide a clue. 